\title{
Cold Preservation of Human Adult Hepatocytes for Liver Cell Therapy
}

\author{
Cedric Duret, $* \dagger$ Daniel Moreno, $\neq$ Anangi Balasiddaiah, $\neq 1$ Solene Roux, $* \dagger$ Phillipe Briolotti, $* \dagger$ \\ Edith Raulet, ${ }^{*} \dagger$ Astrid Herrero, ${ }^{*} \dagger \S$ Helene Ramet,,$[$ Christine Biron-Andreani, $\mathbb{\text { I }}$ \\ Sabine Gerbal-Chaloin, $* \dagger$ Jeanne Ramos, $* \dagger \#$ Francis Navarro, $* \dagger \S$ Jean Hardwigsen, $* *$ \\ Patrick Maurel, $* \dagger$ Rafael Aldabe, $*$ and Martine Daujat-Chavanieu $* \dagger, \dagger \dagger$ \\ *INSERM, U1040, Institut de Recherche en Biothérapie, F-34295 Montpellier, France \\ †Université Montpellier 1, UMR 1040, F-34295 Montpellier, France \\ $\ddagger$ Gene Therapy and Hepatology Area, Center for Applied Medical Research (CIMA), University of Navarra, Pamplona, Spain \\ $\S$ Department of General and Liver Transplant Surgery, CHU Montpellier Hôpital Saint Eloi, Montpellier, France \\ IIHemophilia Treatment Center, CHU Montpellier Hôpital Saint-Eloi, Montpellier, France \\ \#Department of Pathology, CHU Montpellier Hôpital Gui de Chauliac, Montpellier, France \\ **Department of Digestive Surgery and Liver Transplantation, AP-HM, Hôpital La Conception, Marseille, France \\ $\dagger+C H U$ Montpellier Hôpital Saint-Eloi, Institut de Recherche en Biothérapie, Montpellier, France
}

\begin{abstract}
Hepatocyte transplantation is a promising alternative therapy for the treatment of hepatic failure, hepatocellular deficiency, and genetic metabolic disorders. Hypothermic preservation of isolated human hepatocytes is potentially a simple and convenient strategy to provide on-demand hepatocytes in sufficient quantity and of the quality required for biotherapy. In this study, first we assessed how cold storage in three clinically safe preservative solutions (UW, HTS-FRS, and IGL-1) affects the viability and in vitro functionality of human hepatocytes. Then we evaluated whether such cold-preserved human hepatocytes could engraft and repopulate damaged livers in a mouse model of liver failure. Human hepatocytes showed comparable viabilities after cold preservation in the three solutions. The ability of fresh and cold-stored hepatocytes to attach to a collagen substratum and to synthesize and secrete albumin, coagulation factor VII, and urea in the medium after 3 days in culture was also equally preserved. Coldstored hepatocytes were then transplanted in the spleen of immunodeficient mice previously infected with adenoviruses containing a thymidine kinase construct and treated with a single dose of ganciclovir to induce liver injury. Engraftment and liver repopulation were monitored over time by measuring the blood level of human albumin and by assessing the expression of specific human hepatic mRNAs and proteins in the recipient livers by RT-PCR and immunohistochemistry, respectively. Our findings show that cold-stored human hepatocytes in IGL-1 and HTS-FRS preservative solutions can survive, engraft, and proliferate in a damaged mouse liver. These results demonstrate the usefulness of human hepatocyte hypothermic preservation for cell transplantation.
\end{abstract}

Key words: Cell therapy; Transplantation; Human hepatocytes; Hypothermic preservation; Liver; Engraftment

\section{INTRODUCTION}

Currently, liver transplantation is the gold standard treatment for hepatic failure, hepatocellular deficiency, and genetic metabolic disorders. However, this invasive procedure is expensive, associated with high morbidity, and is limited by the shortage of transplantable organs. Biotherapy, such as the use of a bioartificial liver or hepatocyte transplantation, could be an alternative for transient or permanent liver metabolic support. Hepatocytes isolated from livers that are not suitable for orthotopic transplantation could provide an additional chance for patients on waiting lists and a unique opportunity for those who are not eligible for liver transplant. The development of approaches for hepatocyte preparation in specialized centers with the aim of providing on-demand sufficient amounts of good quality hepatocytes could broaden the scope of these therapies (42). As the hepatocyte source (i.e., donors) is inherently unpredictable, it is necessary to establish the best strategy to identify and prepare the recipient patients and to handle and dispatch the cells to be injected. Hepatocyte cryopreservation and banking is theoretically the most adapted practical solution. Freezing/

Received April 7, 2014; final acceptance January 19, 2015. Online prepub date: January 23, 2015.

${ }^{1}$ Current affiliation: Department of Laboratory Medicine, Karolinska Institute, 17177 Stockholm, Sweden.

Address correspondence to Martine Daujat-Chavanieu, INSERM U1040, Institut de Recherche en Biothérapie, Hôpital St Eloi 80, Avenue Augustin Fliche, 34295 Montpellier Cedex 5, France. Tel: +0033 4673306 23; Fax: +0033 46733 04 59; E-mail: martine.daujat@inserm.fr 
thawing protocols have been considerably improved over the years, and now cryopreserved hepatocytes are viable, with some metabolic activities close to those of fresh hepatocytes (e.g., CYP) for at least a short period after thawing $(28,44)$. However, poor attachment to culture substrates is often reported, thus limiting their long-term in vitro use and questions their ability to adhere to the hepatic sinusoidal endothelium after transplantation $(24,47,49)$. Indeed, there is evidence that cryopreserved hepatocytes are less efficient than fresh hepatocytes for transplantation $(9,33)$. Alternatively, freshly isolated hepatocytes could be cold stored in conditions similar to those used for liver preservation before transplantation $(17,19,30,36,39)$. This approach has been widely explored in experimental settings using different organ preservative solutions or defined culture media and isolated $(2,34,37,40,41)$ or cultured hepatocytes $(8,26,39)$, mainly of animal origin. Most of these studies focused on the recovery of the cell metabolic capacities after rewarming, with the aim of providing a convenient cell source for in vitro drug discovery platforms. To our knowledge, the engraftment and repopulation of a damaged liver by cold-stored human hepatocytes has never been tested. We thus studied the impact of hypothermic preservation in three clinically safe (i.e., drug-agency approved) and animal product-free preservative solutions on the viability and in vitro functionality of human hepatocytes and also after transplantation in mice with liver damage (32). Hypothermic preservation slows down cell metabolism and leads to structural membrane damage and reduction of the ATP intracellular pool $(16,30,46)$; therefore, different solutions have been elaborated to counteract these problems. For this study we chose three cold storage solutions designed for use in organ transplantation (13). The University of Wisconsin (UW) solution was developed in the late 1980s to prevent cell swelling, intracellular acidosis, injury from oxygen-free radicals, and to maintain the ATP levels (45). Since then, it has become the standard solution for the preservation of most organs for transplantation and also of many cell types in suspension, including human hepatocytes shipped for transplantation in clinical trials $(15,19)$. It is now considered as the reference for clinical applications. Hypothermosol-FRS (HTS-FRS) is an improved formulation of the intracellular-like solution Hypothermosol (6) that suppresses free radical formation in cells undergoing prolonged hypothermic preservation (29) and preserves human hepatocyte integrity and metabolizing functions (36). We also included Institut Georges Lopez 1 (IGL-1), another organ preservative solution that contains polyethylene glycol (PEG), as colloid, and has a high extracellular sodium/potassium ratio. These features should improve liver preservation (4). IGL-1 was found to be as efficient and safe as UW while less expensive (10); however, it has never been used for cold preservation of isolated human hepatocytes.

\section{MATERIALS AND METHODS}

\section{Chemicals}

Culture media Ham-F12 and William's medium E, additives, and collagenase type IV were purchased from Sigma-Aldrich (Saint-Quentin Fallavier, France), fetal calf serum from Lonza (Levallois-Perret, France), and cytokines/ growth factors from Peprotech (Neuilly sur Seine, France). Hepatocytes in suspension were preserved in IGL-1 solution (Institut Georges Lopez, Lissieu, France), University of Wisconsin solution (UW; VIASPAN; Bristol-Myers Squibb, Rueil Malmaison, France), or HTS-FRS (BioLife Solutions Inc., Bothell, WA, USA).

\section{Human Hepatocyte Isolation}

Liver samples were obtained either after resection for medical reasons (primary tumor or metastasis) or from donors when the liver was considered unsuitable for organ transplantation. The use of human liver tissues to prepare hepatocytes for research purposes was approved by the French National Ethics Committees and local legal instances. Informed consent was obtained from each patient or family prior to surgery. Information on the donors of the livers used in this study is shown in Table 1.

Hepatocytes were isolated by using a two-step perfusion protocol and cultured as described previously by our laboratory $(7,11,14,38)$. Briefly, several veins apparent on the cut edge of the lobectomy were used for sequential perfusions with a washing buffer, with a calcium-chelating buffer made according to Pichard et al. (38), and then with a collagenase solution. After gentle disruption of the tissue and filtration, the post-collagenase homogenate was centrifuged at low speed $(50 \times g$ for $5 \mathrm{~min})$ to pellet the hepatocytes. Hepatocytes were then resuspended in "short-term culture medium" (38) supplemented with $2 \%$ heat-inactivated fetal calf serum, and seeded at $2.6 \times 10^{5}$ viable cells $/ \mathrm{cm}^{2}$ on collagen type I-coated wells (Becton Dickinson, Pont De Claix, France). After overnight attachment, the medium

Table 1. Characteristics of the Human Liver Donors

\begin{tabular}{|c|c|c|c|}
\hline Liver Identity & Sex & Age & Pathology \\
\hline Liver 1 & $\mathrm{~F}$ & 25 & $\begin{array}{l}\text { Primary hepatic neuroendocrine } \\
\text { tumor }\end{array}$ \\
\hline Liver 2 & $\mathrm{~F}$ & 67 & $\begin{array}{l}\text { Metastasis from colorectal } \\
\text { carcinoma }\end{array}$ \\
\hline Liver 3 & $\mathrm{~F}$ & 39 & $\begin{array}{l}\text { Metastasis from melanoma } \\
\text { carcinoma }\end{array}$ \\
\hline Liver 4 & M & 61 & $\begin{array}{l}\text { Metastasis from colorectal } \\
\text { carcinoma }\end{array}$ \\
\hline Liver 5 & M & 52 & Liver donor organ \\
\hline Liver 6 & $\mathrm{H}$ & 66 & $\begin{array}{l}\text { Metastasis from colorectal } \\
\text { carcinoma }\end{array}$ \\
\hline Liver 7 & $\mathrm{~F}$ & 40 & $\begin{array}{l}\text { Metastasis from colorectal } \\
\text { carcinoma }\end{array}$ \\
\hline
\end{tabular}


and unattached cells were removed, and fresh "long-term medium" (38) was added. All experiments were carried out in duplicate.

\section{Cold Storage}

Hepatocytes were resuspended at the indicated concentrations in the preservative solutions in 50-ml polycarbonate tubes (Becton Dickinson) and left undisturbed for $12,24,48$, or $96 \mathrm{~h}$ at $2-6^{\circ} \mathrm{C}$. At the different time points, cells in preservative solutions were diluted with four volumes of "short-term culture medium," washed once again with $50 \mathrm{ml}$ "short-term culture medium," and classically centrifuged at $200 \times g$ for 5 min before seeding.

\section{Cell Viability}

Viability was estimated based on the trypan blue exclusion method. After cold storage, hepatocytes in suspension were washed twice in "short-term culture medium" (38) and incubated at room temperature with $0.4 \%$ trypan blue (Invitrogen, Cergy Pontoise, France) for $5 \mathrm{~min}$. For each sample, the percentage of viable cells was calculated in duplicate.

\section{Cell Attachment Measurement}

After cold storage, hepatocytes were washed in "shortterm culture medium" and seeded at the same concentration as freshly isolated hepatocytes (FIH) (plated at a density calculated based on their viability before cold storage). Their attachment was estimated by measuring the total amount of proteins recovered after overnight plating. Wells were washed twice with PBS (Invitrogen) to remove unattached cells and medium, and then cells were detached and lysed in reporter lysis buffer (Promega, Charbonnieres, France) through three freezing/thawing cycles. Protein concentration was determined using the bicinchoninic acid (BCA) method (Interchim, Montluçon, France) according to the manufacturer's recommendations. Absorbance at $562 \mathrm{~nm}$ was measured using a Mithras LB940 microplate reader (Berthold Technologies, Thoiry, France), and the total protein concentration per well was calculated and expressed as the percentage of the protein concentration of freshly isolated hepatocytes.

\section{RNA Analysis by RT-PCR}

Total RNA was extracted from human hepatocytes (primary cultures) or mouse tissues using the TRIzol reagent, according to the manufacturer's recommendations (Invitrogen), and $500 \mathrm{ng}$ of total RNA was reverse transcribed using random hexaprimers and the MMLV Reverse Transcriptase Kit (Invitrogen). Primer sequences are in Table 2. When possible, primer pairs were designed from different exons to avoid false-positive results in case of contamination by genomic DNA.

Quantitative PCR was performed using the Roche Molecular Biochemicals Light Cycler system (Roche Diagnostic, Meylan, France) with the following program:

Table 2. Sequences of Primer Pairs Used for Quantitative and Semiquantitative RT-PCR Analysis

\begin{tabular}{cl}
\hline Experiment/Genes & \multicolumn{1}{c}{ Primer Sequences } \\
\hline $\begin{array}{l}\text { Phenotype (quantitative RT-PCR) } \\
\text { C/EBP } \alpha\end{array}$ & \\
C/EBP $\alpha$ & AGGGACTTGGGGCTTGGAAC \\
& GACCCCCATCGCAGTGAGTT \\
HNF1 $\alpha$ & GCCCTCGCAGGTCAAGAGCA \\
& TTGAACAAGTTCCGCAGGGTG \\
HNF4 $\alpha$ & CCAGCATCCCAGCAGATCCT \\
& GTGTCCATGGCCAGCTTGTG \\
RPLP0 & CGCAGATGTGTGTGAGTCCA \\
& CAGTGCCGAGGGACAATGTA \\
Transplantation (semiquantitative RT-PCR) & TCGACAATGGCAGCATCTAC \\
hAAT & CCCTTGACCTTTCAGCAAG \\
& GCTGAAGACCTTAGTGATGC \\
hAlbumin & ACTTCGGGATGAAGGGAAGGC \\
hCPS1 & CATCATTTCCACTTCGGCAATG \\
h/mRPLP0 & GTTGTCTGAACCAAGCAGCA \\
hRPLP0 & CGCAGTGTGCGGATACTAGA \\
& GGCAAGAACACCATGATGCG \\
& CGGACACCCTCCAGAAAGCGA \\
\hline & TCGACAATGGCAGCATCTAG \\
& GCCTTGACCTTTCAGCAAG \\
\hline
\end{tabular}


one step at $95^{\circ} \mathrm{C}$ for $10 \mathrm{~min}, 55$ cycles of denaturation at $95^{\circ} \mathrm{C}$ for $15 \mathrm{~s}$, annealing at $65^{\circ} \mathrm{C}$ for $15 \mathrm{~s}$, elongation at $72^{\circ} \mathrm{C}$ for $15 \mathrm{~s}$. The amplification specificity was verified by determining the product melting curve. Relative expression values were calculated with the LightCycler480 software (Roche Diagnostics) and normalized to the expression of ribosomal protein, large, P0 (RPLP0). RNA from human muscle cells (kindly provided by Dr. G. Carnac, INSERM U1046, Montpellier, France) was included as negative control.

Human liver chimerism in transplanted mice was analyzed by semiquantitative PCR using the Taq Platinum set (Invitrogen) and a Techne TC-512 gradient thermocycler (IMLAB, Lille, France) with the following program: one step at $94^{\circ} \mathrm{C}$ for 2 min, cycles of denaturation at $94^{\circ} \mathrm{C}$ for $30 \mathrm{~s}$, annealing at $60^{\circ} \mathrm{C}$ for $30 \mathrm{~s}$, and elongation at $72^{\circ} \mathrm{C}$ for $30 \mathrm{~s}$, and final step at $72^{\circ} \mathrm{C}$ for $5 \mathrm{~min}$. Primers are listed in Table 2. PCR products were visualized under UV light after migration in $2 \%$ agarose gels containing the SyberSafe DNA gel stain (Invitrogen). The percentage of chimerism was evaluated using RNA samples in which increasing concentrations of human liver RNA (from $1 \%$ to $100 \%$ ) were mixed with mouse liver RNA. The species specificity and efficiency of all primers (including the $\mathrm{h} / \mathrm{m}$ RPLP0 forward primer that exhibits one mismatch toward human RPLP0 mRNA) were previously validated using mouse and human liver cDNA as templates.

\section{Quantification of Human Albumin, Coagulation Factor VII, and Urea Production and Secretion}

Human albumin in the supernatants of hepatocytes or in the serum of chimeric mice following blood sampling from the facial vein was measured using a sandwich ELISA assay according to the manufacturer's instructions (Bethyl Laboratory, Montgomery, TX, USA). Human albumin concentration was calculated by nonlinear regression analysis with the GraphPad Prism 5 software (GraphPad Software Inc., La Jolla, CA, USA).

We adapted a previously described ELISA assay (Diagnostica Stago, Asnieres, France) (7) to quantify the amount of coagulation factor VII in the hepatocyte culture supernatant. The culture medium was used as a negative control.

Spontaneous production and secretion of urea by hepatocytes was quantified using the QuantiChrom Urea Assay Kit (Gentaur, Paris, France), a colorimetric test.

All these analyses were performed in duplicate, and the values in hepatocyte supernatants were normalized to the amount of total protein extracted from the same well and quantified with the BCA method (Interchim, Montluçon, France).

\section{Liver Damage Induction and Human Hepatocyte Transplantation}

We used, with some minor modifications, a recently described mouse model in which, following drug-induced liver damage, the liver can be efficiently repopulated by xenogeneic hepatocytes $(3,32)$. Male Balb/C Rag2 $2^{\text {tm1Fwa }}$ $\mathrm{Cd} 3 \mathrm{~g}^{\text {tm1Amk }}$ mice (4-6 weeks old, bred at CIMA, Pamplona, Spain) were intravenously inoculated with $5 \times 10^{9} \mathrm{PFU}$ of recombinant adenoviruses expressing herpes simplex virus thymidine kinase (AdTk). In these mice, liver damage is characterized by inflammation accompanied by increased hepatocyte size and enlarged nuclei and provides a growth advantage for transplanted human hepatocytes. The AdTk-GCV effect is maintained for 10 weeks and then is progressively resolved, as indicated by regenerative nodules (32). As soon as the human liver perfusion was planned, a single dose of $50 \mathrm{mg} / \mathrm{kg}$ ganciclovir (GCV; Roche) was intraperitoneally administered to induce subacute liver damage. Human hepatocytes were isolated at the production site (Montpellier, France) and were cold preserved in HTS-FRS or IGL- 1 at $1 \times 10^{6}$ cells $/ \mathrm{ml}$ on ice during shipment to the transplantation site (Pamplona, Spain). Thirteen to $15 \mathrm{~h}$ after isolation, $1.5 \times 10^{6}$ viable human hepatocytes suspended in $100 \mu \mathrm{l}$ PBS were inoculated in the spleen of mice. Freshly isolated hepatocytes were not available. As cultured human hepatocytes were previously shown to be a suitable source of cells for the generation of chimeric livers in this model (32), hepatocytes from the same donor were cultured in long-term medium for 7 days and were transplanted in a group of mice used as controls.

\section{FACING PAGE}

Figure 1. Impact of cold preservation on human hepatocyte viability and attachment. Different concentrations $\left(0.1,1,10\right.$, and $25 \times 10^{6}$ cells/ $\mathrm{ml}$ ) of human hepatocytes were preserved in suspension at $2-8^{\circ} \mathrm{C}$ using different organ preservation solutions (IGL-1, HTS-FRS, and UW) for $16 \mathrm{~h}$. (A) Cell viability was then assessed by using the trypan blue exclusion method (freshly isolated hepatocytes, FIH). (B) Hepatocytes were then seeded on collagen type I-coated plates according to their viability before hypothermic preservation, and their morphology and confluence were visualized by phase contrast microscopy after $16 \mathrm{~h}$ in culture. (C, D) Hepatocytes were preserved in suspension $\left(1 \times 10^{6}\right.$ cells $\left./ \mathrm{ml}\right)$ at $2-8^{\circ} \mathrm{C}$ in the different organ preservation solutions for up to 4 days. At different time points $(12,24,48,96 \mathrm{~h})$ cells were washed, and (C) their viability was assessed by using the trypan blue exclusion method, and (D) their attachment capacity was evaluated by seeding on collagen type I-coated plates according to their viability before hypothermic preservation and by quantifying the total protein amount per well after $16 \mathrm{~h}$ in culture. Results are expressed as the percentage of the value measured in cells plated immediately after isolation (time 0). Statistical analysis was performed using an ANOVA followed by the Dunnett's post hoc test multiple group comparison, with UW value as a reference $(* p<0.05)$. Scale bar: $100 \mu \mathrm{m}$. 
A

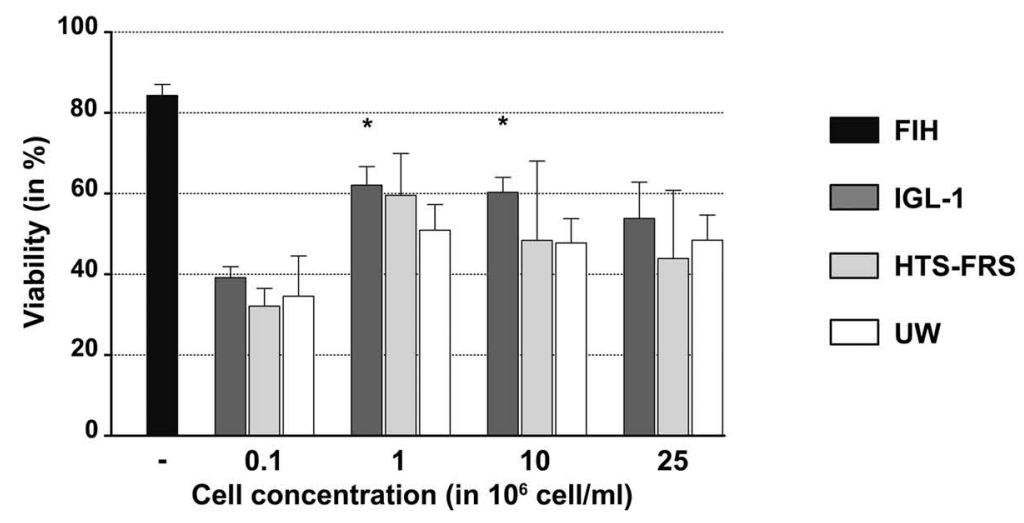

B

Cell concentration (in $10^{6} \mathrm{cell} / \mathrm{ml}$ )

GL-1
0.1
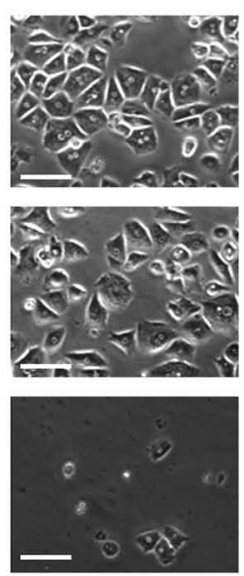

1
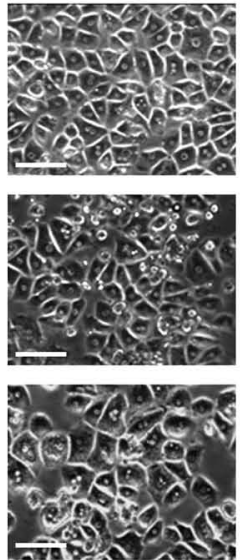

10
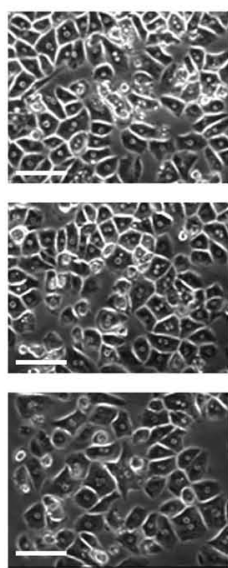

25
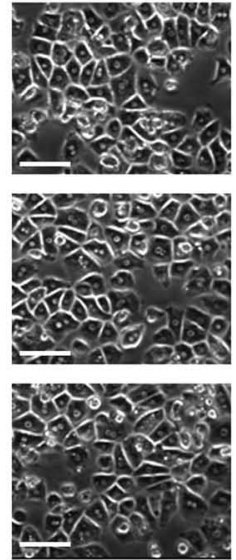

C

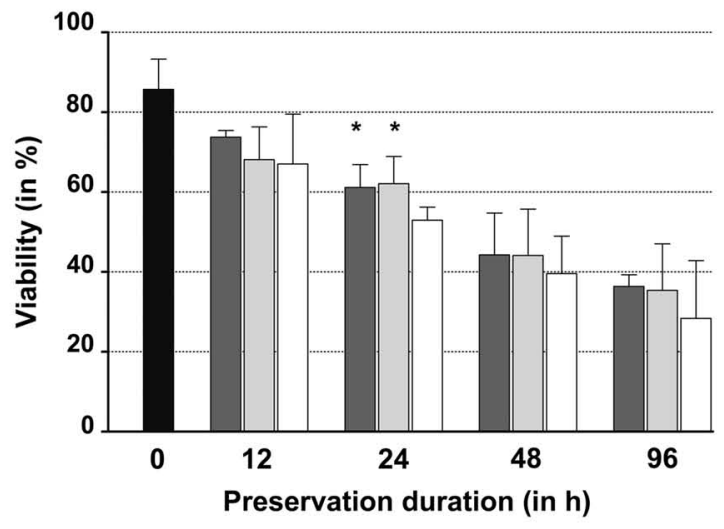

D

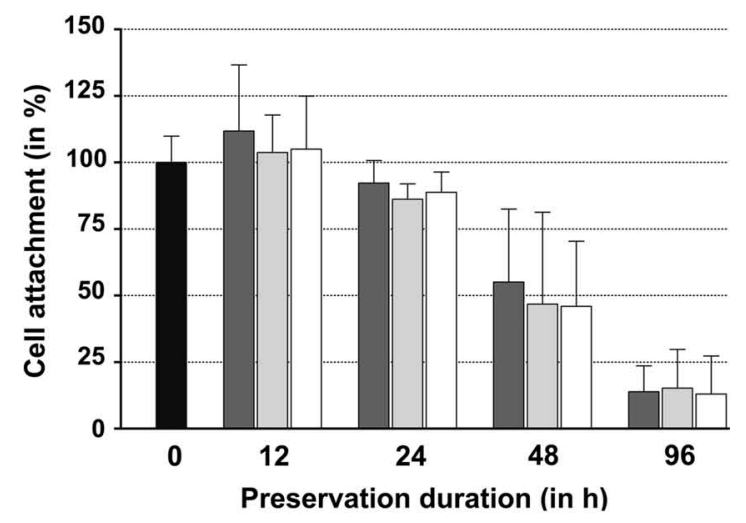

HTS-FRS UW 
Then animals received intravenously $100 \mu \mathrm{l}$ of human $\mathrm{AB}$ serum (Sigma-Aldrich) and were treated with antibiotics at $25 \mathrm{mg} / \mathrm{ml}$ in drinking water (enrofloxacin; Bayer HealthCare, Barcelona, Spain) for 1 week. Blood was collected by retro-orbital bleeding once per week, and cell engraftment was followed by quantifying serum human albumin (ELISA assay; Bethyl Laboratories Inc.), starting at 3 weeks posttransplantation when the injected human serum was cleared. The serum levels of alanine and aspartate transaminase (ALT, AST) in transplanted mice were quantified using a Cobas C311 analyzer (Roche). The study protocol was approved by the Animal Experimentation Ethics Committee of the University of Navarra, Spain (permit Nos. 041-07 and 095-09).

\section{Immunohistochemistry}

Immunohistochemical staining was performed using the EnVisionTM+ System (Dako, Glostrup, Denmark) according to the manufacturer's recommendations. Paraffin liver sections ( $3 \mu \mathrm{m}$ thick) were sliced, dewaxed, and hydrated, and some of them were stained with hematoxylin (Panreac, Catelar del Vallès, Spain) and eosin (H\&E) (Merck, Darmstadt, Germany) for routine histology. If necessary, heat-induced antigen retrieval (AR) was performed by incubating sections at $95^{\circ} \mathrm{C}$ in $0.01 \mathrm{M}$ Tris- $1 \mathrm{mM}$ EDTA buffer $(\mathrm{pH}=9)$ (Sigma-Aldrich) in a Pascal pressure chamber (S2800; Dako) for 30 min. Proteolytic-induced AR was performed by incubating sections in $20 \mu \mathrm{g} / \mathrm{ml}$ proteinase $\mathrm{K}$ (Sigma-Aldrich) at $37^{\circ} \mathrm{C}$ for $30 \mathrm{~min}$. Endogenous peroxidase was blocked with $3 \% \mathrm{H}_{2} \mathrm{O}_{2}$ (Panreac) in deionized water for $10 \mathrm{~min}$. Sections were washed in TBS- $0.05 \%$ Tween 20 (TBS-T) (Fluka, Madrid, Spain) and incubated with primary antibodies [anti-hCK-18, 1:100; M7010 (Dako); anti-albumin, 1:8,000 (Bethyl Laboratories)] at $4^{\circ} \mathrm{C}$ overnight. After rinsing in TBS-T, sections were incubated with the relevant secondary antibodies (Dako). Peroxidase activity was revealed using DAB+ (K3468; Dako), and sections were lightly counterstained with Harris hematoxylin (Panreac). Finally, they were dehydrated in a graded series of ethanol, cleared in xylene, and mounted in DPX (SigmaAldrich). Slides were scanned (Montpellier RIO Imaging facilities, INM Montpellier, France) using a Nanozoomer Slide Scanner (Hamamatsu Photonics, Massy, France), and virtual slides were viewed using the NDP.view software (Hamamatsu Photonics).

\section{Statistical Analysis}

Experiments on each liver were carried out in duplicate. Results were expressed as the mean \pm SEM. Oneway repeated measures analysis of variance (ANOVA) followed by the Dunnett's post hoc test multiple group comparison was used to analyze group differences. Data were analyzed by GraphPad Prism software version 5 (GraphPad Software Inc.). Values of $p<0.05$ were considered significant $(p<0.05, p<0.01, p<0.001)$.

\section{RESULTS}

Impact of Hypothermic Preservation on Viability, Morphology, and Attachment of Human Hepatocytes

To determine the optimal cold-storage conditions for human hepatocytes, first we assessed the effect of the concentration at which cells were cold stored on their viability. To this aim, human hepatocytes were stained with trypan blue after $16 \mathrm{~h}$ of cold storage in three different preservative solutions (UW, IGL-1, and HTS-FRS). Overall, cold storage reduced cell viability compared to freshly isolated hepatocytes (FIHs) (Fig. 1A), and the deleterious effect was strongest (viability around $40 \%$ ) at the lowest cell concentration $\left(0.1 \times 10^{6} \mathrm{cell} / \mathrm{ml}\right)$. At intermediate cell concentrations $\left(1-10 \times 10^{6} / \mathrm{ml}\right)$, viability ranged from $48 \%$ to $62 \%$, depending on the storage solutions. IGL-1 solution allowed a slight but significantly better recovery of viable human hepatocytes than UW. The trypan blue exclusion method is based on cell membrane integrity and does not portend cell functionalities. Conversely, cell attachment to a substratum is an energy-demanding process indicative of cell vitality. Cell attachment was thus assessed in parallel to viability measurements, assuming that hepatocytes that attach and spread on the substrate are viable and functional. Hepatocytes that had been cold preserved in suspension at different concentrations (see Fig. 1A) for $16 \mathrm{~h}$ were thus seeded on collagen type I-coated plates at a density calculated based on their viability before cold storage (i.e., FIH viability). Their ability to form a monolayer was assessed by phase contrast microscopy after overnight culture. Hepatocytes exhibited the same characteristic polygonal

\section{FACING PAGE}

Figure 2. Phenotype and functionality of human hepatocytes cultured after hypothermic preservation. Hepatocytes were seeded on collagen type I-coated dishes directly after isolation (FIH) or after cold preservation in suspension in the different solutions for 12 or $24 \mathrm{~h}$ and cultured for 3 days. (A) The mRNA levels of hepatic genes encoding liver-enriched transcription factors (HNF1 $\alpha, H N F 4 \alpha$, $\mathrm{C} / \mathrm{EBP} \alpha$, and $\mathrm{C} / \mathrm{EBP} \beta$ ) were quantified by qRT-PCR and expressed as the percentage of their expression in FIHs. (B) Hepatocyte synthetic functions were assessed by quantifying the secretion of albumin, coagulation factor VII, and urea in the medium. Statistical analysis was performed using an ANOVA followed by the Dunnett's post hoc test multiple group comparison, with FIH value as a reference $(* p<0.05)$. 
A


B
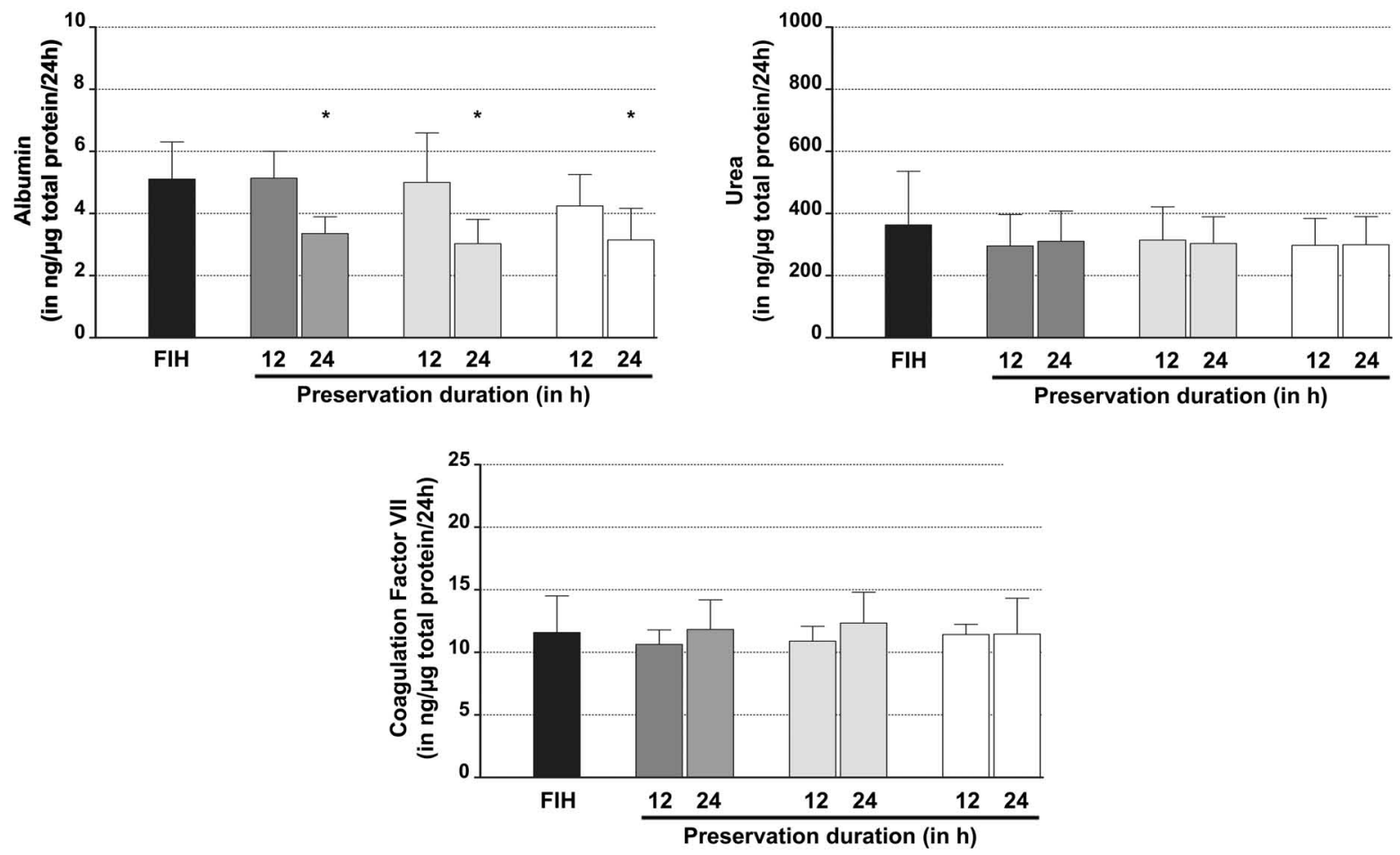

IGL-1

$\square$ HTS-FRS 
morphology before and after cold storage in the three solutions (Fig. 1B), and cell confluence varied depending on the storage conditions (cell concentration and solution), as observed for cell viability (Fig. 1A). Based on these results and on literature data (36), for the subsequent experiments, hepatocytes were cold stored in suspension at a concentration of $1 \times 10^{6}$ cells $/ \mathrm{ml}$. We then examined the impact of the cold storage duration on cell viability and attachment (Fig. 1C). For all hepatocyte samples (isolated from three different livers with viabilities of $78 \%, 95 \%$, and $84 \%$ ), cell viability declined progressively with the storage time (from $72 \%$ after $12 \mathrm{~h}$ down to $35 \%$ after 96 $\mathrm{h}$ of storage) in all solutions. No difference was observed concerning the three cold storage solutions, except after $24 \mathrm{~h}$ of hypothermic preservation when cells stored in IGL-1 or HTS-FRS showed a significantly better viability than cells preserved in UW. Finally, human hepatocytes were seeded on collagen type I-coated plates before and after cold storage, and plating efficiency was evaluated $16 \mathrm{~h}$ later by quantifying the total protein amount per well (Fig. 1D). As with cell viability, the cell attachment declined progressively over storage time, from $100 \%$ after $12 \mathrm{~h}$ down to $13 \%$ after $96 \mathrm{~h}$ of cold storage, but without any significant difference between the three preservative solutions. The difference observed between changes in viability and attachment can be explained by the fact that cells with little membrane damage may be stained blue, but are still viable and have the potential to repair and recover. Overall, this experiment indicates that viable hepatocytes after cold storage in the three preservative solutions retain their adhesive properties.

\section{Phenotype and Functionality of Human Hepatocytes After Cold Preservation}

The deleterious effect of hypothermia/hypoxia, such as apoptosis and mitochondrial dysfunction, can be revealed and/or amplified during the rewarming period $(12,39,43)$. A viability of $60 \%$ is the consensual acceptable limit for the use of isolated hepatocytes in clinical settings; thus, we were mostly interested in analyzing the phenotype of hepatocytes selected for this criteria. Therefore, the functionality of human hepatocytes after 12 and $24 \mathrm{~h}$ of hypothermic preservation in the different solutions was assessed after return to normoxic temperature and 3-day culture and compared to that of hepatocytes seeded directly after isolation.

In these experiments, fresh (FIHs) and cold-preserved hepatocytes were seeded based on their viability to establish a confluent cell monolayer in order to avoid the cell dedifferentiation observed in subconfluent human hepatocyte primary cultures $(21,27)$. Q-PCR analysis (Fig. $2 \mathrm{~A})$ revealed that the mRNA expression of HNF1 $\alpha$, $\mathrm{HNF} 4 \alpha, \mathrm{C} / \mathrm{EBP} \alpha$ and $\mathrm{C} / \mathrm{EBP} \beta$ (liver-enriched transcription factors that are critical for the highly differentiated hepatocyte phenotype and function) was well maintained after $12 \mathrm{~h}$ of cold storage. After $24 \mathrm{~h}$, a slight, but not significant, decrease (due to the interindividual variability among liver donors) compared to FIHs was observed. Similarly, the ability of FIHs and cold-stored hepatocytes to synthesize and secrete coagulation factor VII and urea (the clinical biological parameters usually followed in patients with liver disease) in the extracellular medium after 3 days of culture was preserved, but albumin secretion was significantly decreased after $24 \mathrm{~h}$ of cold storage (Fig. 2B). Overall, these results demonstrate that cold preservation up to $12 \mathrm{~h}$ does not dramatically affect the phenotype and synthetic functions of human hepatocytes in primary culture, regardless of the preservative solution used.

\section{Transplantation of Cold-Preserved Human Hepatocytes}

We then investigated whether cold-preserved hepatocytes in IGL-1 and HTS-FRS solutions could be used for cell transplantation. For this purpose, we used a simplified mouse model of liver injury (32) that relies on the rapid induction of liver damage in a temporally controlled manner following a single intraperitoneal injection of GCV at high dose in immunodeficient mice infected with AdTk. The experimental protocol is described in Figure 3A.

In this pilot study, two independent transplantation experiments (Experiment I: mice with mild liver damage-ALT mean value between 300 and $450 \mathrm{IU} / \mathrm{ml}$; Experiment II: mice with sustained liver damage-ALT mean value between 500 and $800 \mathrm{IU} / \mathrm{ml}$ ) were carried out. For each experiment, hepatocytes from a single liver were used after cold storage in IGL-1 or HTS-FRS (one group of mice for each solution; three to seven mice/group) or after culture (only for Experiment II). Hepatocyte viability

\section{FACING PAGE}

Figure 3. Engraftment of cold-preserved human hepatocytes in mice infected with AdTk after induction of mild liver damage by injection of ganciclovir. (A) Schematic of the transplantation experiments: immunodeficient mice infected with adenoviruses expressing thymidine kinase (AdTk) received intraperitoneally a single high dose of ganciclovir as soon as the human liver perfusion was planned. Isolated human hepatocytes were cultured or preserved in suspension $\left(1 \times 10^{6}\right.$ cells $\left./ \mathrm{ml}\right)$ on ice in the different solutions (IGL-1 and HTS-FRS) and shipped to the transplantation site in Pamplona, Spain. They were injected in the spleen of mice with mild (Experiment I) or sustained (Experiment II) liver damage 13 to $15 \mathrm{~h}$ after liver dissociation and cold preservation or after a 7-day culture period (D7). Human hepatocyte engraftment was evaluated by measuring the production/secretion of human albumin in the serum of recipient mice at different time points after transplantation (3 to 9 weeks) in Experiment I (B) and Experiment II (C). Values are the mean albumin concentration per group. 
A

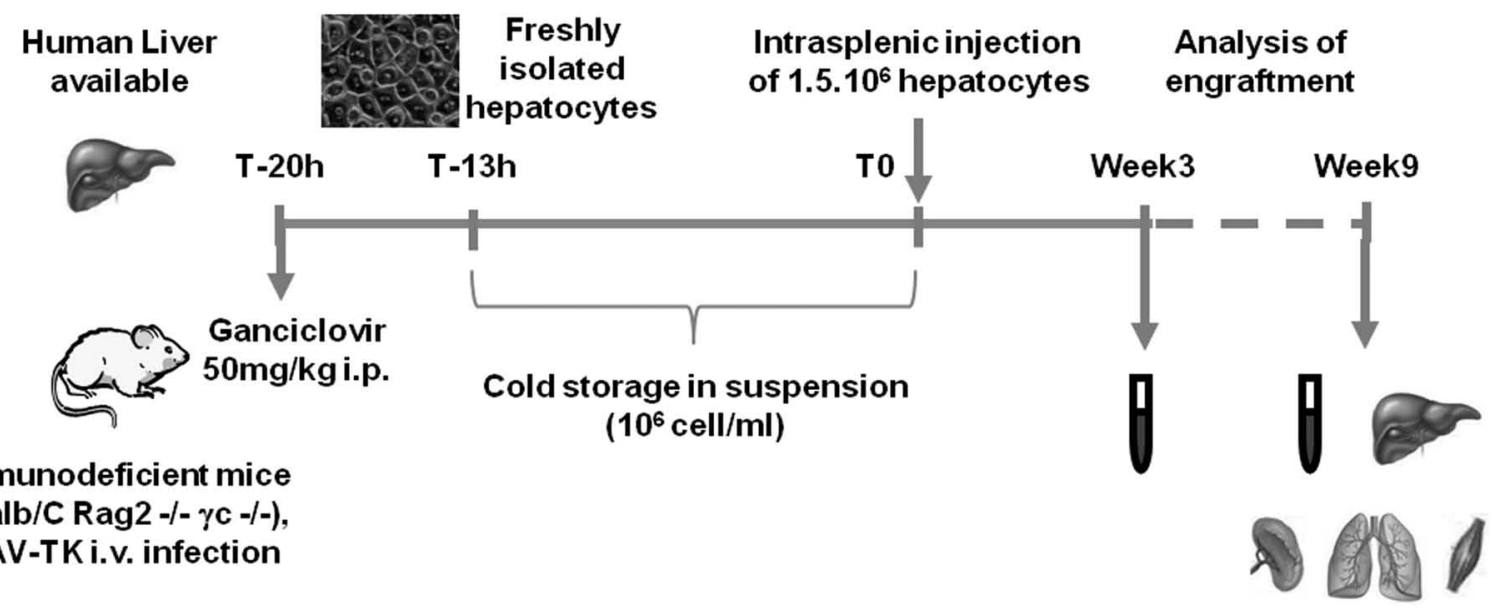

B

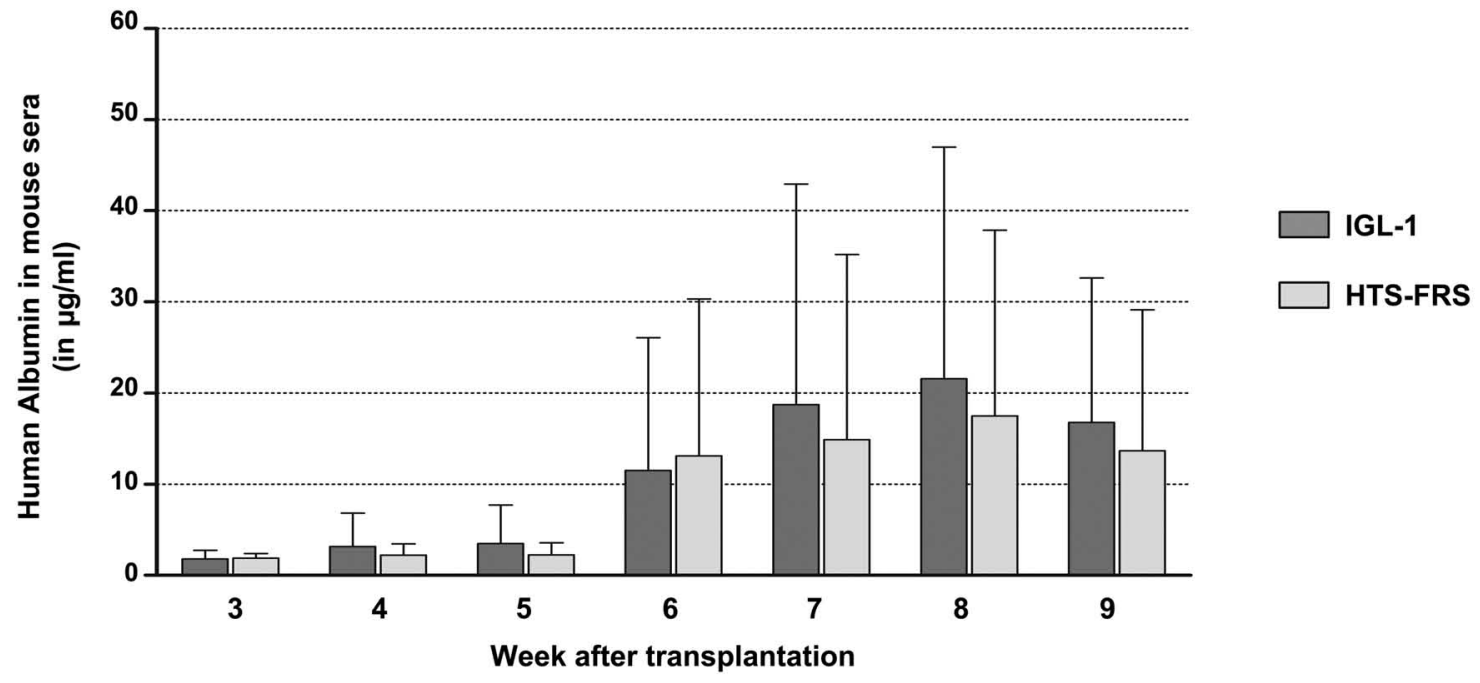

C

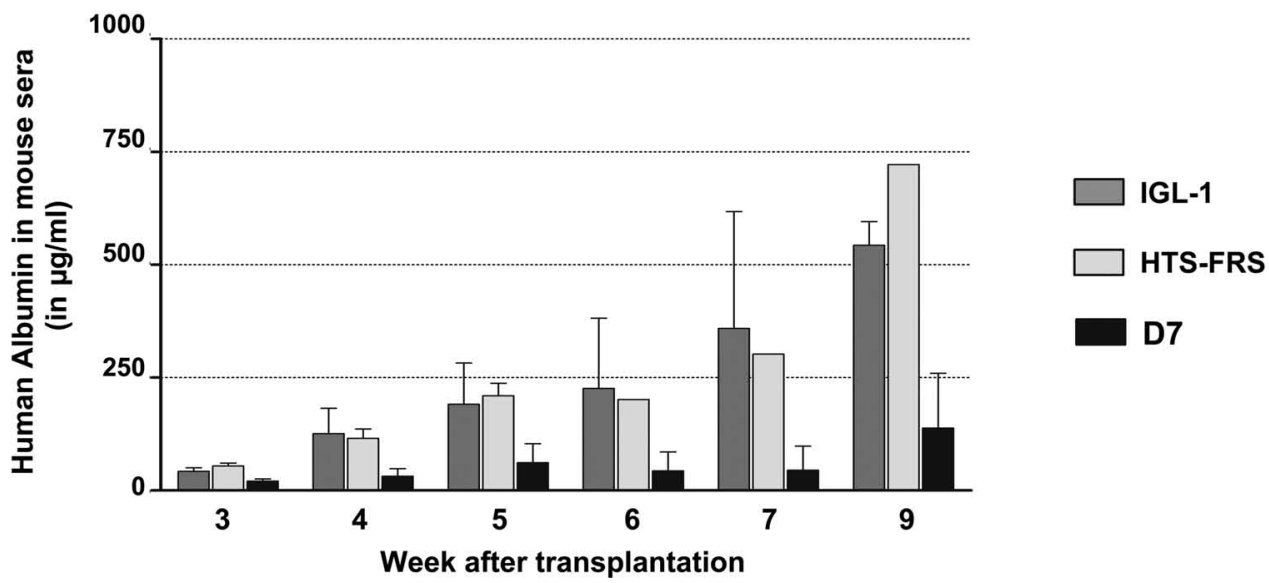


Table 3. Transplantation of Cold-Preserved Human Hepatocytes to Rescue Mice With Liver Failure

\begin{tabular}{|c|c|c|c|c|}
\hline \multirow[b]{2}{*}{ Hepatocytes } & \multicolumn{2}{|c|}{ Human Hepatocytes (Viability) } & \multicolumn{2}{|c|}{$\begin{array}{l}\text { Transplanted Mice Survivors } \\
\text { (Day/Week of Sacrifice) }\end{array}$} \\
\hline & Experiment I & Experiment II & Experiment $\mathrm{I}(n=7)$ & Experiement II $(n=3)$ \\
\hline Fresh & $72 \pm 4 \%$ & $86 \pm 2 \%$ & - & - \\
\hline \multicolumn{5}{|l|}{ Cold-stored } \\
\hline IGL-1 & $62 \pm 7.7 \%$ & $62 \pm 5 \%$ & 5/7 (day 2) 5/7 (9 weeks) & 3/3 (9 weeks) \\
\hline HTS-FRS & $70 \pm 1.7 \%$ & $66 \pm 4.4 \%$ & 5/7 (day 2) 5/7 (9 weeks) & $1 / 3$ (9 weeks) \\
\hline \multicolumn{5}{|l|}{ Cultured } \\
\hline Day 7 & - & $85 \%$ & - & 3/3 (9 weeks) \\
\hline Control & - & - & 2/2 (9 weeks) & 3/3 (9 weeks) \\
\hline
\end{tabular}

Hepatocyte viability and mice survival outcomes in two independent transplantation experiments (Experiments I and II). For each experiment, hepatocytes from one single liver were used. Ratios refer to the number of surviving mice/ total number of mice at the time point indicated in parentheses.

after cold storage at the time of the intrasplenic injection (T0) ranged between $62 \%$ and $70 \%$, corresponding to a recovery between $72 \%$ and $97 \%$, when referred to the FIH viability (Table 3 ). Four mice died from surgical complications at day 2 postgraft in Experiment I (Table 3). The remaining mice survived until sacrifice at week 9 after transplantation, whereas some of the animals included in Experiment II died around week 5 after transplantation due to illness related to the liver injury (Table 3). Transplantation outcomes of Experiments I and II are presented in Figures 3 and 4. Engraftment was monitored over time by measuring human albumin in the recipients' blood. Its concentration was very variable, even within the same group and in animals that received hepatocytes from the same liver. Overall, human albumin serum concentration gradually increased between weeks 3 and 9 posttransplantation. However, it was much lower in animals included in Experiment I (mild liver injury) (Fig. 3B) than in those in Experiment II (high liver injury) (Fig. 3C), as expected. The presence of human hepatocytes within the host liver was confirmed by assessing the mRNA expression of several human hepatic markers (Fig. 4A, B). Based on the albumin production, hepatocytes that had been cold stored in IGL-1 and HTS-FRS showed equivalent engraftment capacity in both Experiments I and II. Indeed, the levels of circulating human albumin increased in a comparable manner in both HTS-FR and IGL-1 groups, reaching around $20 \mu \mathrm{g} / \mathrm{ml}$ and $720 \mu \mathrm{g} / \mathrm{ml}$ in Experiments I and II, respectively, at the end of the experiment (week 9). In contrast, human albumin production by human hepatocytes transplanted after 7 days in culture (D7) was significantly lower and remained stable over time (Fig. 3C). Repopulation of mouse livers by human hepatocytes was evaluated also by immunohistochemistry on a small number of animals (Fig. 4C). Five weeks after cell graft, human hepatocytes could be identified with antibodies against human albumin and CK18 (data not shown) in the liver lobes. They were organized in small clusters, reflecting their selective expansion after successful engraftment. Four weeks later ( 9 weeks after transplantation), the clusters of human hepatocytes were larger, suggesting several rounds of cell division in a subset of transplanted cells. At this stage, in H\&E-stained sections, clusters of human hepatocytes could be clearly differentiated from mouse hepatocytes by their size and the paler cytoplasm, as previously described $(31,32,48)$. Native regenerative nodules were also visible (Fig. 4C). Human hepatocytes were not found in the lungs, and only some residual hepatocytes were observed in the spleen (Fig. 4D), especially after injection of D7 hepatocytes, as revealed by the detection of human hepatic markers in this organ (Fig. 4B). In conclusion, cold-preserved human

\section{FACING PAGE}

Figure 4. Analysis of chimeric livers in AdTk/GCG-treated mice after transplantation of cold-preserved or cultured human hepatocytes. Human hepatocyte engraftment was evaluated at 9 weeks posttransplantation at the end of Experiment I (A) and Experiment II (B) by semiquantitative RT-PCR analysis of the expression of human hepatic genes in the liver, spleen, lung, and muscle. Humanmouse RNA solutions containing decreasing percentages (from 100\% to 1\%) of human mRNA were included to estimate the human/ mouse liver chimerism. (C) Immunohistochemistry was performed to specifically detect human CK18 (hCK18) and albumin (hAlb) in chimeric livers. The presence of growing human hepatocyte nodules was evidenced at week 9 posttransplantation. Native regenerative nodules were observed after hematoxylin and eosin (H\&E) staining. Scale bar: $100 \mu \mathrm{m}$. (D) Dissemination of the infused human hepatocytes in the recipients' body was investigated after sacrifice at the end of the experiment ( 9 weeks posttransplantation) by immunohistochemistry with antibodies against human CK18 in lung, muscle, and spleen tissue sections. Scale bar: $1 \mathrm{~mm}$. 
A

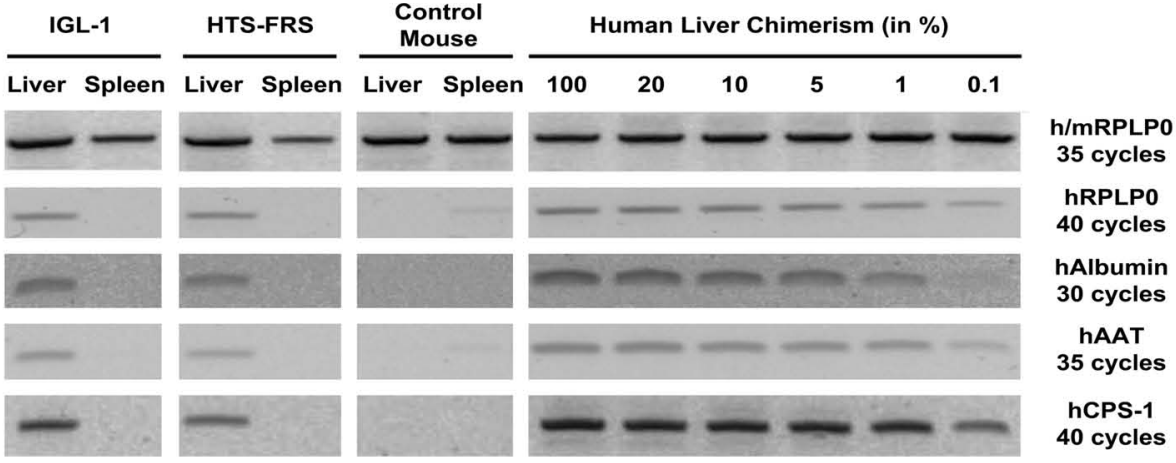

B
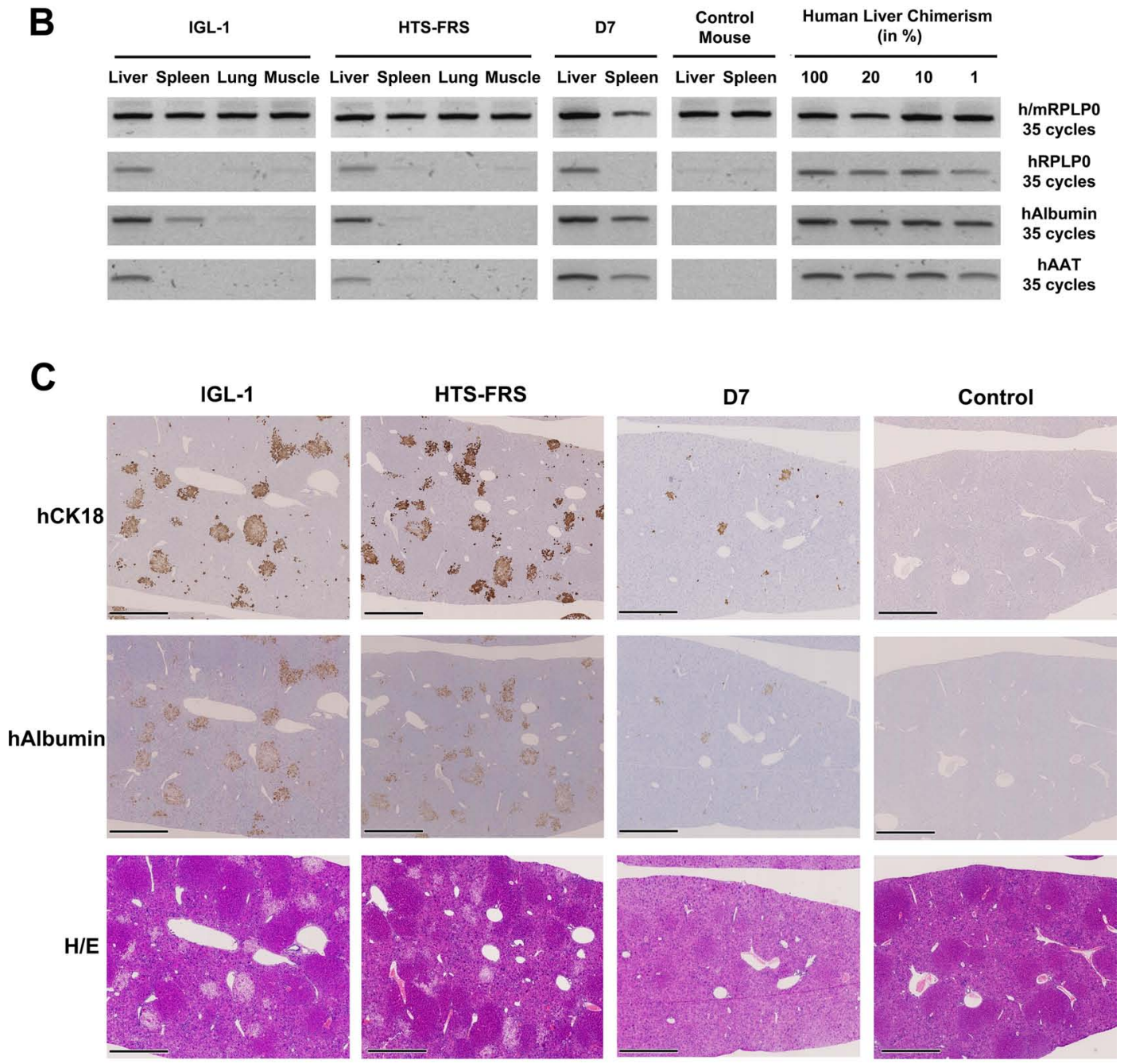

D
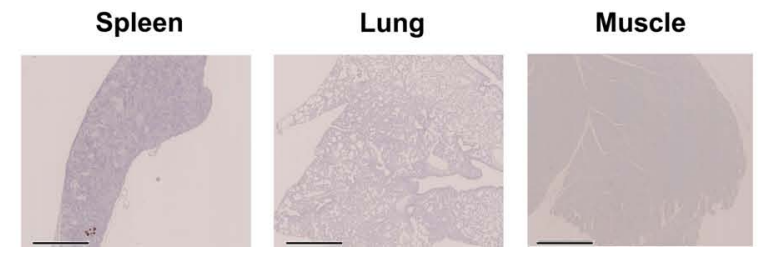
hepatocytes retain their ability to engraft and repair a damaged liver, whatever the preservative solution, and display normal biological functions, as shown by the albumin production over a 9-week period after transplantation. Cultured human hepatocytes can also engraft and proliferate in damaged livers, as previously shown (32), but not as efficiently as cold-preserved hepatocytes.

\section{DISCUSSION}

The objectives of this study were to evaluate hypothermic conditions for preserving FIHs in clinically safe preservative solutions and then to determine whether and to what extent cold-stored hepatocytes can repopulate a damaged liver in a mouse model.

Plating efficiency is a valuable criterion of cell vitality and is assumed to correlate with their engraftment capacity in the liver. As described by others, we found that viability and attachment of human hepatocytes after hypothermic storage in suspension were dependent on cell density and on the preservation period. After short hypothermic storage $(12 \mathrm{~h})$, hepatocytes in primary culture were as healthy and functional as freshly isolated cells. Previous studies reported comparable gene expression profiles (44) and xenobiotic metabolism capacity and clearance predictions in human hepatocytes in suspension after cold storage and in freshly isolated cells $(19,36)$. We found that human hepatocytes could be cold stored at $4{ }^{\circ} \mathrm{C}$ for up to $24 \mathrm{~h}$ without significant decrease in functional integrity, as assessed by their ability to attach on a substratum and to produce and secrete urea and factor VII, and with a viability higher than $60 \%$, which is the threshold limit value currently accepted as an insurance of hepatocyte quality for biotherapy programs (1). Moreover, we did not observe any clear specific effect of the three storage solutions, although IGL-1 and HTSFRS seemed to give better results than UW concerning cell survival. These results are in agreement with recent data showing the superiority of HTS-FRS compared to UW for the maintenance of the metabolic activity of human hepatocytes in vitro after $48 \mathrm{~h}$ and $72 \mathrm{~h}$ of cold storage (36). However, in our study the difference between UW and HTS-FRS was not as significant as in this previous work. Our results are similar to those reported by Gramignoli et al. showing that critical hepatic functions, analyzed in 47 human hepatocyte preparations, were well maintained in hepatocytes after cold storage in UW solution for up to 48 $\mathrm{h}$, although in our hands UW is not as performing as stated in this work (19). The metabolic activity of animal hepatocytes also was reported to be maintained after cold storage in UW solution for $48 \mathrm{~h}$ (35). These discrepancies could be related to the age, underlying pathology and medication taken by the liver donors, the impact of the ischemic time on the liver samples and/or species differences (22), and also to the cell dissociation and isolation procedures (collagenases and proteases ratio and activities, composition of the perfusion buffers) that can impact on cell conservation methods (20,34, and unpublished data). Concerning the IGL-1 solution, no other data are currently available regarding its ability to preserve the viability and functionality of human or animal hepatocytes.

Although we observed a decrease in cell viability after $24 \mathrm{~h}$ of cold storage, it has to be noted that important synthetic activities required for clinical applications, such as urea synthesis and factor VII secretion, were still well maintained in the surviving cells after 3 days in culture. Urea synthesis, a complex process involving several enzymes, is a good indicator of the degree of mitochondrial preservation. Like others, we found that urea metabolism is better maintained than albumin secretion, which seems more sensitive to long-term cold preservation (19). This could be related to the irreversible cytoskeleton disorganization that is associated with long-term cooling and rewarming and that affects the cell transport dynamics $(25,46)$.

We then evaluated to which extent cold preservation in IGL-1 and HTS-FRS solutions influences human hepatocyte survival and function after transplantation into a suitable animal model. Comparison with freshly isolated cells was not included because our intent was to simulate the clinical situation that occurs when hepatocytes are prepared in specialized centers far away from the transplantation site. For the same reason, the chosen mouse model of AdTk/GCV-induced liver damage (32) was very convenient for performing on-demand transplantation studies, as the availability of human livers is unpredictable. Using this experimental model, we show that human hepatocytes can survive, engraft, and proliferate in a chronically damaged liver after cold preservation in IGL-1 and HTS-FRS solutions. Although it is difficult to measure the exact extent of the contribution of human hepatocytes in the chimeric mouse liver, we think that about $10-15 \%$ of hepatocytes were of human origin based on the expression of human-specific liver function markers (by immunohistochemistry and RT-PCR analysis) in the liver of the recipient mice. This estimation is in accordance with the data by Hasegawa et al. (23) showing a high correlation between liver chimerism and plasma concentration of human albumin in recipient mice. Although preliminary (due to the small number of animals included in the study), our data suggest that IGL-1 and HTS-FRS represent alternative conservative solutions useful for biotherapy programs based on hepatocyte transplantation.

IGL-1 previously showed some level of protection against the immune response following kidney and pancreatic islet grafts, possibly due to the "immunocamouflage" provided by PEG interaction with membranes (50). Moreover, according to Ben Mosbah et al., IGL-1 offers a better protection to steatotic livers, which are the main available source of human hepatocytes for 
liver biotherapy, against the deleterious effects of cold ischemia-reperfusion injury than the UW solution (5). Whether these protective effects are also effective on hepatocytes isolated from such livers is an interesting question that deserves further studies.

Compared to cryopreservation, hypothermia is a milder technique that does not require the use of potentially deleterious chemicals, liquid nitrogen, or special equipment for cell storage and might allow shipping to remote sites for transplantation. Its main disadvantage is the relatively short period of time that cells can be preserved. However, recent advances in preservation methods based either on supercoiling (51) or on the formulation of new solutions better adapted to cold storage has already allowed increasing the preservation time of rat hepatocytes up to 1 week with improved cell survival and function $(8,40)$. The application of these strategies to the preservation of primary human hepatocytes has already given some promising results (39). Hepatocytes may also be preserved by culturing. We show here that our long-term culture conditions favor human hepatocyte survival in monolayer $(7,14,18,38,52)$ and also maintain their ability to engraft and proliferate in a damaged liver microenvironment. However, engraftment and proliferation were less efficient than after cold storage in suspension. Moreover, the culture process introduces additional steps that may increase cell loss after detachment, economic cost, and safety concerns.

In conclusion, we show that primary human hepatocytes can be hypothermically preserved up to $24 \mathrm{~h}$ while maintaining a metabolic activity similar to that of freshly isolated cells. This cheap procedure, based on clinically safe and commonly used preservative solutions, allows the easy handling of large quantities of hepatocytes isolated from precious donor livers, optimizing their use in clinical biotherapy programs. Indeed, cold preservation gives the time to deliver cells to distant transplantation centers and facilitates their repeated use when several cell infusions or refilling of an extracorporal bioartificial liver bioreactor are required. Overall, our results demonstrate that human hepatocytes could be successfully cold preserved in clinically safe and commonly used preservative solutions for clinical applications.

ACKNOWLEDGEMENTS: This work has been funded by the Région Languedoc-Roussillon/Communauté de Travail des Pyrénées. The authors thank Ms. Elisabetta Andermarcher and Ms. Natalie Funakoshi for the professional editing. The authors declare no conflicts of interest.

\section{REFERENCES}

1. Alexandrova, K.; Griesel, C.; Barthold, M.; Heuft, H. G.; Ott, M.; Winkler, M.; Schrem, H.; Manns, M. P.; Bredehorn, T.; Net, M.; Vidal, M. M.; Kafert-Kasting, S.; Arseniev, L.
Large-scale isolation of human hepatocytes for therapeutic application. Cell Transplant. 14(10):845-853; 2005.

2. Bakala, A.; Karlik, W.; Wiechetek, M. Hypothermic storage of equine isolated hepatocytes. Pol. J. Vet. Sci. 10(1):11-18; 2007.

3. Balasiddaiah, A.; Moreno, D.; Guembe, L.; Prieto, J.; Aldabe, R. Hepatic differentiation of mouse iPS cells and analysis of liver engraftment potential of multistage iPS progeny. J. Physiol. Biochem. 69(4):835-845; 2013.

4. Ben Abdennebi, H.; Elrassi, Z.; Scoazec, J. Y.; Steghens, J. P.; Ramella-Virieux, S.; Boillot, O. Evaluation of IGL-1 preservation solution using an orthotopic liver transplantation model. World J. Gastroenterol. 12(33):5326-5330; 2006.

5. Ben Mosbah, I.; Rosello-Catafau, J.; Franco-Gou, R.; Abdennebi, H. B.; Saidane, D.; Ramella-Virieux, S.; Boillot, O.; Peralta, C. Preservation of steatotic livers in IGL-1 solution. Liver Transpl. 12(8):1215-1223; 2006.

6. Bessems, M.; Doorschodt, B. M.; van Vliet, A. K.; van Gulik, T. M. Preservation of rat livers by cold storage: A comparison between the University of Wisconsin solution and Hypothermosol. Ann. Transplant. 9(2):35-37; 2004.

7. Biron-Andreani, C.; Bezat-Bouchahda, C.; Raulet, E.; Pichard-Garcia, L.; Fabre, J. M.; Saric, J.; Baulieux, J.; Schved, J. F.; Maurel, P. Secretion of functional plasma haemostasis proteins in long-term primary cultures of human hepatocytes. Br. J. Haematol. 125(5):638-646; 2004.

8. Dai, J.; Meng, Q. Differential function of protective agents at each stage of the hypothermic preservation of hepatocytes. J. Biochem. 149(6):739-745; 2011.

9. David, P.; Alexandre, E.; Audet, M.; Chenard-Neu, M. P.; Wolf, P.; Jaeck, D.; Azimzadeh, A.; Richert, L. Engraftment and albumin production of intrasplenically transplanted rat hepatocytes (Sprague-Dawley), freshly isolated versus cryopreserved, into Nagase analbuminemic rats (NAR). Cell Transplant. 10(1):67-80; 2001.

10. Dondero, F.; Paugam-Burtz, C.; Danjou, F.; Stocco, J.; Durand, F.; Belghiti, J. A randomized study comparing IGL-1 to the University of Wisconsin preservation solution in liver transplantation. Ann. Transplant. 15(4):7-14; 2010.

11. Duret, C.; Vinci, B.; Sbrana, T.; Klieber, S.; Maurel, P.; Daujat-Chavanieu, M.; Ahluwalia, A. Cultivation of human hepatocytes in the quasi-vivo system: From isolation and seeding to quantification of xenobiotic-metabolizing enzyme expression and activity. In: Haycock, J.; Ahluwalia, A.; Wilkinson, J. M., eds. Cellular in vitro testing: Methods and protocols. Singapore: Pan Stanford Publishing; 2015:35-52.

12. Duval, M.; Plin, C.; Elimadi, A.; Vallerand, D.; Tillement, J. P.; Morin, D.; Haddad, P. S. Implication of mitochondrial dysfunction and cell death in cold preservation-warm reperfusion-induced hepatocyte injury. Can. J. Physiol. Pharmacol. 84(5):547-554; 2006.

13. Feng, X. N.; Xu, X.; Zheng, S. S. Current status and perspective of liver preservation solutions. Hepatobiliary Pancreat. Dis. Int. 5(4):490-494; 2006.

14. Ferrini, J. B.; Pichard, L.; Domergue, J.; Maurel, P. Longterm primary cultures of adult human hepatocytes. Chem. Biol. Interact. 107(1-2):31-45; 1997.

15. Fox, I. J.; Chowdhury, J. R.; Kaufman, S. S.; Goertzen, T. C.; Chowdhury, N. R.; Warkentin, P. I.; Dorko, K.; Sauter, B. V.; Strom, S. C. Treatment of the Crigler-Najjar syndrome type I with hepatocyte transplantation. N. Engl. J. Med. 338(20):1422-1426; 1998. 
16. Fuller, B. The effects of cooling on mammalian cells. In: Fuller, B.; Grout, B., eds. Clinical applications of cryobiology. Boca Raton, FL: CRC Press; 1991:1-22.

17. Fuller, B. J.; Petrenko, A. Y.; Rodriguez, J. V.; Somov, A. Y.; Balaban, C. L.; Guibert, E. E. Biopreservation of hepatocytes: Current concepts on hypothermic preservation, cryopreservation, and vitrification. Cryo Letters 34(4): 432-452; 2013.

18. Gondeau, C.; Briolotti, P.; Razafy, F.; Duret, C.; Rubbo, P. A.; Helle, F.; Reme, T.; Ripault, M. P.; Ducos, J.; Fabre, J. M.; Ramos, J.; Pecheur, E. I.; Larrey, D.; Maurel, P.; Daujat-Chavanieu, M. In vitro infection of primary human hepatocytes by HCV-positive sera: Insights on a highly relevant model. Gut 63(9):1490-1500; 2014.

19. Gramignoli, R.; Dorko, K.; Tahan, V.; Skvorak, K. J.; Ellis, E.; Jorns, C.; Ericzon, B. G.; Fox, I. J.; Strom, S. C. Hypothermic storage of human hepatocytes for transplantation. Cell Transplant. 23(9):1143-1151; 2014.

20. Gramignoli, R.; Green, M. L.; Tahan, V.; Dorko, K.; Skvorak, K. J.; Marongiu, F.; Zao, W.; Venkataramanan, R.; Ellis, E. C.; Geller, D.; Breite, A. G.; Dwulet, F. E.; McCarthy, R. C.; Strom, S. C. Development and application of purified tissue dissociation enzyme mixtures for human hepatocyte isolation. Cell Transplant. 21(6):1245-1260; 2012.

21. Greuet, J.; Pichard, L.; Ourlin, J. C.; Bonfils, C.; Domergue, J.; Le Treut, P.; Maurel, P. Effect of cell density and epidermal growth factor on the inducible expression of CYP3A and CYP1A genes in human hepatocytes in primary culture. Hepatology 25(5):1166-1175; 1997.

22. Guillouzo, A.; Guyomard, C.; Fautrel, A.; Chesne, C. Storage of isolated hepatocytes. In: Berry, M. N.; Edwards, A. M., eds. The hepatocyte review. Dordrecht: Kluwer Academic Publishers 2000;125-145.

23. Hasegawa, M.; Kawai, K.; Mitsui, T.; Taniguchi, K.; Monnai, M.; Wakui, M.; Ito, M.; Suematsu, M.; Peltz, G.; Nakamura, M.; Suemizu, H. The reconstituted 'humanized liver' in TK-NOG mice is mature and functional. Biochem. Biophys. Res. Commun. 405(3):405-410; 2011.

24. Hewitt, N. J. Optimisation of the cryopreservation of primary hepatocytes. Methods Mol. Biol. 640:83-105; 2010.

25. Hovanyecz, P.; Guibert, E. E.; Pellegrino, J. M.; Rodriguez, J. V.; Sigot, V. Extended cold storage of cultured hepatocytes impairs endocytic uptake during normothermic rewarming. Cryobiology 66(2):112-120; 2013.

26. Janssen, H.; Janssen, P. H.; Broelsch, C. E. Celsior solution compared with University of Wisconsin solution (UW) and histidine-tryptophan-ketoglutarate solution (HTK) in the protection of human hepatocytes against ischemia-reperfusion injury. Transpl. Int. 16(7):515-522; 2003.

27. LeCluyse, E. L. Human hepatocyte culture systems for the in vitro evaluation of cytochrome $\mathrm{P} 450$ expression and regulation. Eur. J. Pharm. Sci. 13(4):343-368; 2001.

28. Li, A. P. Human hepatocytes: Isolation, cryopreservation and applications in drug development. Chem. Biol. Interact. 168(1):16-29; 2007.

29. Mathew, A. J.; Baust, J. M.; Van Buskirk, R. G.; Baust, J. G. Cell preservation in reparative and regenerative medicine: Evolution of individualized solution composition. Tissue Eng. 10(11-12):1662-1671; 2004.

30. Meng, Q. Hypothermic preservation of hepatocytes. Biotechnol. Prog. 19(4):1118-1127; 2003.

31. Meuleman, P.; Libbrecht, L.; De Vos, R.; de Hemptinne, B.; Gevaert, K.; Vandekerckhove, J.; Roskams, T.; LerouxRoels, G. Morphological and biochemical characterization of a human liver in a uPA-SCID mouse chimera. Hepatology 41(4):847-856; 2005.

32. Moreno, D.; Balasiddaiah, A.; Lamas, O.; Duret, C.; Neri, L.; Guembe, L.; Galarraga, M.; Larrea, E.; Daujat-Chavanieu, M.; Muntane, J.; Maurel, P.; Riezu, J. I.; Prieto, J.; Aldabe, R. Usage of adenovirus expressing thymidine kinase mediated hepatocellular damage for enabling mouse liver repopulation with allogenic or xenogenic hepatocytes. PLoS One 8(9): e74948; 2013.

33. Nishitai, R.; Koch, C. A.; Ogata, K.; Knudsen, B. E.; Plummer, T. B.; Butters, K. A.; Platt, J. L. Toward the survival and function of xenogeneic hepatocyte grafts. Liver Transpl. 11(1):39-50; 2005.

34. Oesch, F.; Abdel-Latif, H.; Diener, B. Viability, attachment efficiency, and xenobiotic metabolizing enzyme activities are well maintained in EDTA isolated rat liver parenchymal cells after hypothermic preservation for up to 3 days in University of Wisconsin solution. In Vitro Cell. Dev. Biol. Anim. 31(8):590-594; 1995.

35. Olinga, P.; Merema, M.; Slooff, M. J.; Meijer, D. K.; Groothuis, G. M. Influence of 48 hours of cold storage in University of Wisconsin organ preservation solution on metabolic capacity of rat hepatocytes. J. Hepatol. 27(4):738-743; 1997.

36. Ostrowska, A.; Gu, K.; Bode, D. C.; Van Buskirk, R. G. Hypothermic storage of isolated human hepatocytes: A comparison between University of Wisconsin solution and a hypothermosol platform. Arch. Toxicol. 83(5):493-502; 2009.

37. Pahernik, S. A.; Thasler, W. E.; Mueller-Hoecker, J.; Schildberg, F. W.; Koebe, H. G. Hypothernic storage of pig hepatocytes: Influence of different storage solutions and cell density. Cryobiology 33(5):552-566; 1996.

38. Pichard, L.; Raulet, E.; Fabre, G.; Ferrini, J. B.; Ourlin, J. C.; Maurel, P. Human hepatocyte culture. Methods Mol. Biol. 320:283-293; 2006.

39. Pless, G.; Sauer, I. M.; Rauen, U. Improvement of the cold storage of isolated human hepatocytes. Cell Transplant. 21(1):23-37; 2012.

40. Pless Petig, G.; Singer, B. B.; Rauen, U. Cold storage of rat hepatocyte suspensions for one week in a customized cold storage solution-preservation of cell attachment and metabolism. PLoS One 7(7):e40444; 2012.

41. Poullain, M. G.; Fautrel, A.; Guyomard, C.; Chesne, C.; Grislain, L.; Guillouzo, A. Viability and primary culture of rat hepatocytes after hypothermic preservation: The superiority of the Leibovitz medium over the University of Wisconsin solution for cold storage. Hepatology 15(1):97-106; 1992.

42. Puppi, J.; Strom, S. C.; Hughes, R. D.; Bansal, S.; Castell, J. V.; Dagher, I.; Ellis, E. C.; Nowak, G.; Ericzon, B. G.; Fox, I. J.; Gomez-Lechon, M. J.; Guha, C.; Gupta, S.; Mitry, R. R.; Ohashi, K.; Ott, M.; Reid, L. M.; Roy-Chowdhury, J.; Sokal, E.; Weber, A.; Dhawan, A. Improving the techniques for human hepatocyte transplantation: Report from a consensus meeting in London. Cell Transplant. 21(1):1-10; 2012.

43. Rauen, U.; Polzar, B.; Stephan, H.; Mannherz, H. G.; de Groot, H. Cold-induced apoptosis in cultured hepatocytes and liver endothelial cells: Mediation by reactive oxygen species. FASEB J. 13(1):155-168; 1999.

44. Richert, L.; Liguori, M. J.; Abadie, C.; Heyd, B.; Mantion, G.; Halkic, N.; Waring, J. F. Gene expression in human hepatocytes in suspension after isolation is similar to the liver of origin, is not affected by hepatocyte cold storage and cryopreservation, but is strongly changed after hepatocyte plating. Drug Metab. Dispos. 34(5):870-879; 2006. 
45. Southard, J. H.; van Gulik, T. M.; Ametani, M. S.; Vreugdenhil, P. K.; Lindell, S. L.; Pienaar, B. L.; Belzer, F. O. Important components of the UW solution. Transplantation 49(2):251-257; 1990.

46. Stefanovich, P.; Ezzell, R. M.; Sheehan, S. J.; Tompkins, R. G.; Yarmush, M. L.; Toner, M. Effects of hypothermia on the function, membrane integrity, and cytoskeletal structure of hepatocytes. Cryobiology 32(4):389-403; 1995.

47. Stephenne, X.; Najimi, M.; Sokal, E. M. Hepatocyte cryopreservation: Is it time to change the strategy? World J. Gastroenterol. 16(1):1-14; 2010.

48. Tateno, C.; Kataoka, M.; Utoh, R.; Tachibana, A.; Itamoto, T.; Asahara, T.; Miya, F.; Tsunoda, T.; Yoshizato, K. Growth hormone-dependent pathogenesis of human hepatic steatosis in a novel mouse model bearing a human hepatocyte-repopulated liver. Endocrinology 152(4): 1479-1491; 2011.

49. Terry, C.; Hughes, R. D.; Mitry, R. R.; Lehec, S. C.; Dhawan, A. Cryopreservation-induced nonattachment of human hepatocytes: Role of adhesion molecules. Cell Transplant. 16(6):639-647; 2007.

50. Thuillier, R.; Giraud, S.; Favreau, F.; Goujon, J. M.; Desurmont, T.; Eugene, M.; Barrou, B.; Hauet, T. Improving long-term outcome in allograft transplantation: Role of ionic composition and polyethylene glycol. Transplantation 91(6):605-614; 2011.

51. Usta, O. B.; Kim, Y.; Ozer, S.; Bruinsma, B. G.; Lee, J.; Demir, E.; Berendsen, T. A.; Puts, C. F.; Izamis, M. L.; Uygun, K.; Uygun, B. E.; Yarmush, M. L. Supercooling as a viable non-freezing cell preservation method of rat hepatocytes. PLoS One 8(7):e69334; 2013.

52. Vinci, B.; Duret, C.; Klieber, S.; Gerbal-Chaloin, S.; Sa-Cunha, A.; Laporte, S.; Suc, B.; Maurel, P.; Ahluwalia, A.; Daujat-Chavanieu, M. Modular bioreactor for primary human hepatocyte culture: Medium flow stimulates expression and activity of detoxification genes. Biotechnol. J. 6(5):554-564; 2011. 